the pyramidal system. The manifestations are similar to Parkinson's syndrome. In the early stages the changes are reversible, but in more severe intoxication the damage is permanent.

Workers should be examined before employment to exclude neurological disease. Routine examination should be carried out at regular intervals, say three to six months, so that symptoms may be detected as early as possible. Should they develop the workman should be removed from exposure.

The presence of manganese in the atmosphere may be estimated by standard methods. Intoxication can be prevented by provision of appropriate enclosure methods and adequate ventilation to maintain the atmospheric concentration below the recommended threshold of $5 \mathrm{mg}$. per cubic metre of air.

\section{Familial Incidence of Multiple Sclerosis}

Q.-Is there any evidence that multiple sclerosis may be a familial disease, and is therc any genetic reason why a man with the disease should not have children?

A.-There are more sufferers from multiple sclerosis among members of the families of patients with this disease than can be accounted for by chance, and to this extent the disease certainly shows a familial incidence. On the other hand, the distribution of cases within affected families follows no definable genetic pattern. It affects brother and sister more often than parent and child, blood-group and other studies lend no support to genetic linkage, and in particular the second member of a pair of identical twins usually escapes the disease.

For these reasons it is widely held that the familial incidence of multiple sclerosis is more likely to result from common exposure to some factor in the early environment than from actual inheritance. Constitutional and genetic factors probably play some part in determining the susceptibility to nearly every disease, but there is no convincing evidence for a potent genetic contribution to the aetiology of multiple sclerosis.

\section{Pregnancy after Breast Cancer}

Q.-A girl aged 22, who had a radical mastectomy three years ago for carcinoma and has had no recurrence, wants to marry. Is it advisable for her to have children?

A.-Whether a woman who has had a breast cancer should become pregnant is a problem which cannot be answered in general terms, and each case must be judged on its merits.

There is some evidence that occult secondaries which might remain so for many years, if not permanently, are stimulated to grow by pregnancy and so revealed. One must assume on the other hand that there are many instances where patients have been treated for breast cancer and no occult secondaries remain, and others in which occult secondaries may not be stimulated by pregnancy. There is a fairly widespread convention that a patient who remains free from secondary manifestations three years after a radical mastectomy for cancer of the breast may be allowed to have a baby. This, of course, is based on the supposition that if occult secondaries are present the vast majority of them will have revealed themselves by that time, and it is not a bad working rule.

The problem in each individual case resolves itself upon how much the woman wishes to have a child. If it will add meaning to her whole life, then the unknown but, after three years, probably slight additional risk may be accepted. If, on the other hand, it is not very important to her to have a baby, then it is better that she should be enjoined to avoid further pregnancies.

\section{Tuberculosis in Food Handlers}

Q.-Can food handled by a person with open pulmonary tuberculosis be a vehicle for the spread of infection? If not, why should food handlers have to have an $x$-ray examination of the chest before employment?

A.- Since milk infected by bovine tubercle bacilli is the undoubted means of transmission of tuberculosis from cattle to man, and since tubercle bacilli can survive for prolonged periods outside the human body, there is no doubt that food contaminated with tubercle bacilli from any source could be a vehicle for the spread of infection.

\section{Phenobarbitone and Alcohol}

Q.-Can any reliable estimate be made from the concentration of phenobarbitone in the urine of the total amount of drug in the body? Are the clinical effects of alcohol and barbiturates when taken together considered to be synergistic or merely additive?

A.-It is assumed that the first part of the question refers to the patient who has taken an overdose, since it is in these circumstances that knowledge of the amount of phenobarbitone in the body is usually required.

There are many factors which influence the concentration of phenobarbitone in the urine of a patient who has taken an overdose. Renal excretion of barbiturates is directly related to the rate of flow of urine, ${ }^{1}$ and in a poisoned patient this may be profoundly affected by factors such as hypotension and dehydration. Even when these are corrected the rate of phenobarbitone excretion is not of much help, because it does not show whether the serum level is rising or falling. The $p \mathrm{H}$ of the urine also has a marked effect on the amount of barbiturate excreted.'

Another important factor which cannot be deduced from the estimation of barbiturates in the urine is the amount of the drug remaining in the gut. In a severely poisoned patient the intestine may remain inactive for a considerable time, and when, with clinical recovery, normal intestinal activity returns more barbiturate is absorbed and relapse recurs. It is therefore impossible either from the concentration of the drug in the urine or from the amount excreted in the urine in unit time to make an accurate calculation of the total amount of the drug in the body.

The second part of the question deals with a problem which has interested pharmacologists for a long time. Some observations in animals suggest that barbiturates and alcohol are not only synergistic but actually potentiate one another." " Others," however, have questioned this interpretation and conclude that, if allowance is made for the different times of action of the depressant drugs and the different methods of administration, the balance of evidence is in favour of a simple additive effect.

In man the problem is even more complex. There are certainly cases on record in which death has occurred from amounts of alcohol and barbiturates in combination which taken alone would have been perfectly safe. Observations on the effects of alcohol and barbiturates alone and in combination on the ability of subjects to react quickly and accurately also suggest potentiation of the effects of alcohol rather than a simple additive effect.' A good review of this problem is given by Wayne."

\section{REFERENCES}

'Setter, J. G., Freeman, R. B., Maher, J. F., and Schreiner, G. E., Trans., Amer. Soc. artif. intern. Org., 1964, 10, 340. Amer. Soc. artif. Invest., 1957, 36,1217

Dille, J. M., and Ahlquist, R. P., f. Pharmacol. exp. Ther., 1937, 61, 385

Ramsey, H., and Haag, H. B., ibid., 1946, 88, 313.

- Gruber, C. M., Arch. int. Pharmacodyn., 1955, $102,17$.

- Wayne, E. J., f. forens. Med., 1954, 1, 172.

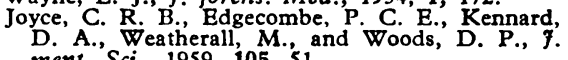
ment. Sci., 1959, 105, 51 .

Wayne, E. J., in Alcohol and Road Traffic, 1963. Proceedings of the Third International Confer1962. B.M.A., London.

\section{Notes and Comments}

Hazards of Veterinary Radiology.-Mr. MICHAEL C. O'RIORDAN (Ministry of Health and Medical Research Council, Radiological Protection Service, Sutton, Surrey) writes : Further to your expert's answer to the question on this subject ("Any Questions?" 4 June, p. 1407) it may be of interest to note that a code of practice for the protection of persons exposed to ionizing radiations in veterinary practice is being prepared by a panel set up by the Radioactive Substances Advisory Committee. The panel is composed of members of the veterinary, medical, and health physics professions, under the chairmanship of Mr. M. K. Lloyd, Central Veterinary Laboratory, Weybridge. Attention was drawn to the setting-up of the panel in the Veterinary Record. ${ }^{1}$

$$
\begin{gathered}
\text { REPERENCB } \\
1 \text { Vet. Rec., 1965, 77, 1531, } 1565 .
\end{gathered}
$$

Diuretics and Potassium Depletion.-Dr. J. C. P. WEBER writes: I was surprised that the answer to the question ("Any Questions?" 4 June, p. 1408) on the use of an alternative diuretic to a thiazide in order to avoid potassium depletion omitted to mention the use of triamterene. There is now a large bibliography on this drug which inhibits the sodiumpotassium exchange in the distal renal tubule. However, it is not an aldosterone antagonist like spironolactone, which was mentioned in the answer, and I would have thought that some reference to triamterene should properly have been made.

\section{Correction}

The name of John Douglas McKee, M.B., B.S., published in the Birthday Honours (18 June, p. 1537) under the heading M.B.E. (Civil Division) should have read John McKee, M.B., Ch.M. 